\title{
ANÁLISE DO LÍQUIDO PERITONEAL NO DIAGNÓSTICO DE CÓLICA EQUINA
}

\author{
Arnaldo Cesar Oliveira Gomes Lira Junior \\ Luiz Henrique da Silva Lima** \\ Manara Alves da Silva Leite ${ }^{* *+}$ \\ Karina Pessoa de Oliveira ${ }^{* * *}$ \\ Pierre Barnabé Escodro ${ }^{*+*+*}$ \\ Marcia Kikuyo Notomi
}

RESUMO: A cólica equina é um processo patológico doloroso de início repentino, que possui repercussão sistêmica e requer um rápido diagnóstico e tratamento, sendo classificada como um abdômen agudo. É uma patologia com a maior taxa de óbito na espécie equina. A análise do líquido peritoneal pode auxiliar na classificação do tipo de doença, na determinação da severidade da lesão abdominal e na origem do problema. Esse estudo avaliou o líquido peritoneal de 12 equinos, sendo dez animais hígidos e dois com síndrome cólica. Após coleta por abdominocentese, as amostras foram analisadas quanto às suas propriedades físicas, celularidade e bioquímica (proteína total, albumina, fosfatase alcalina e glicose). A análise do LP dos animais com cólica diferiu quanto à sua aparência e apresentaram elevação na contagem celular e concentração de proteínas. A avaliação do líquido peritoneal é de realização factível na rotina veterinária pela acessibilidade, rapidez e baixo custo.

PALAVRAS-CHAVES: Fluido peritoneal; Cavalo, Abdômen agudo, Paracentese

\section{ANALYSIS OF PERITONEAL LIQUID IN THE DIAGNOSIS OF HORSE COLIC}

ABSTRACT: Equine colic is a sudden painful pathological process with systemic results and requires quick diagnosis and treatment. It is classified as acute abdominal pain. The pathology ranks highs in horse death. Analysis of the peritoneal liquid may help in the classification of the disease, in the determination of severity in abdominal lesions and in the issue's origin. Peritoneal liquid of 12 horses, ten healthy animals and two with colic syndrome, was analyzed. After abdominocentesis collection, samples were analyzed with regard to physical, cell and biochemical properties (total protein, albumin, alkaline phosphatasis and glucose). Animals' LP analysis with colic differed in aspect, with high cell counts and protein concentration. Evaluation of peritoneal liquid is routine due to accessibility, fastness and low cost.

KEYWORDS: Peritoneal fluid; Horse; Acute abdomen pain; Paracentesis.

\footnotetext{
* Graduando em Medicina Veterinária pela Universidade Federal de Alagoas (UFAL), Alagoas, Brasil. E-mail: juniorecleciane@hotmail.com

${ }^{* *}$ Graduação em Medicina Veterinária pela Universidade Federal de Alagoas (UFAL), Alagoas, Brasil.

${ }^{* * *}$ Graduação em Medicina Veterinária pela Universidade Federal de Alagoas (UFAL), Alagoas, Brasil.

${ }^{* * * *}$ Médica Veterinária. Mestre em ciência animal pela Universidade Federal de Minas Gerais (UFMG), Minas Gerais, Brasil.

${ }^{* * * * *}$ Docente Adjunto IV do Curso de Medicina Veterinária da Universidade Federal de Alagoas e nos Programas de Mestrado em Inovação e Tecnologia Integradas à Medicina Veterinária para o Desenvolvimento Regional (UFAL) e no Mestrado Profissional em Propriedade Intelectual e Transferência de tecnologia para inovação em rede nacional, ponto focal UFA, Brasil.

${ }^{* * * * * *}$ Docente Adjunto IV do Curso de Medicina Veterinária da Universidade Federal de Alagoas (UFAL). Doutora em Clínica Médica pela Universidade de São Paulo, Brasil.
} 


\section{INTRODUÇÃo}

A emergência mais comum na prática de equinos é a síndrome cólica. Aproximadamente 4\% dos cavalos apresentam um episódio de cólica ao ano sendo que $7 \%$ a $10 \%$ apresentam uma lesão que requer correção cirúrgica (COOK; HASSEL, 2014).

A cólica equina é uma dor espasmódica ligada principalmente à distensão do tubo digestivo, dos canais glandulares ou das vias urinárias. É um processo patológico doloroso de início repentino, que possui repercussão sistêmica e requer um rápido diagnóstico e tratamento, encaixando-se na classificação geral de abdômen agudo (BROWN; BERTONE, 2002).

Ampla variedade de agentes causais tem sido implicados como causa de diferentes graus de inflamação no trato gastrointestinal. As formas mais graves de cólica, como obstruções estrangulantes e enterocolite aguda, resultam em graves danos aos tecidos e inflamação (PILH et al., 2015).

Em casos de equinos com cólica $\mathrm{e}$, particularmente, equinos com obstruções ou hipóxia decorrente de torções, o líquido peritoneal (LP) ou efusão peritoneal é considerado uma forma indireta de avaliação das alças intestinais, decorrente do extravasamento de células e proteínas para a cavidade abdominal, alterando a composição normal da efusão (SAULEZ et al., 2005).

0 LP é um ultrafiltrado do sangue, localizado na cavidade peritoneal, entre o peritônio parietal e 0 visceral (MENDES et al., 2000; THOMASSIAN, 2005) e tem como função a lubrificação das vísceras. Sua produção depende de fatores como a pressão oncótica e hidrostática e da permeabilidade capilar e, consequentemente, do fluxo sanguíneo existente no local (THOMASSIAN, 2005).

Nos casos de cólica, a resposta inicial à inflamação intraperitoneal é observada pela alteração da cor do líquido peritoneal, onde sua cor amarela palha fica mais escura, em função do extravasamento de células e proteínas para o líquido peritoneal, elevando sua concentração na cavidade (DEHEER et al., 2002; CAMPEBELL et al., 2007).

A análise da efusão peritoneal garante melhor acompanhamento dos pacientes, podendo ser utilizada na avaliação da resposta terapêutica, além de auxiliar na identificação da necessidade de procedimento cirúrgico, pois permite avaliação do quadro clínico, possibilitando a realização de um prognóstico do animal (SAULEZ et al., 2005).

Existem deficiências em relação à interpretação da análise do LP nos casos de enfermidades abdominais (LHAMAS, 2015). DeHEER (2002) alegou que se a colheita de LP proceder em resultados inconclusivos é mais indicado à realização de colheitas seriadas, evitando complicações na interpretação dos exames.

No Brasil, a importância da análise do LP no diagnóstico afecções abdominais de equinos e asininos também tem ganhado destaque. Nessa última década, estudos com líquido peritoneal de cavalos foram realizados e seus efeitos de processo obstrutivos (DI FILIPP0 et al., 2009; DI FILIPPO et al., 2010; DI FILIPPO et al., 2012; NOGUEIRA et al., 2013, VIERA et al, 2018), parasitários (LLAMAS et al., 2015) e da castração em equinos (DI FILIPPO et al, 2014; DI FILIPP0 et al., 2016) e asininos (BARROS et al., 2018).

A obtenção do líquido peritoneal é realizado pela paracentese abdominal, sendo considerada uma prática fácil e segura para 0 animal, além do baixo custo. É 0 teste laboratorial mais esclarecedor para auxiliar a classificação do tipo de doença e também para determinar a severidade da lesão abdominal (DUESTERDIECK-ZELLMER et al., 2014). Nos cavalos com cólica, a análise do líquido peritoneal é um meio indireto de avaliação das alças intestinais, pois quando apresentam hipóxia em decorrência de torções, obstruções, infartos e ou outras alterações ocorrerá passagem de células e proteína para o líquido peritoneal, alterando sua composição normal (FEITOSA, 2004).

Esta pesquisa teve como objetivo analisar 0 líquido peritoneal de equinos hígidos e equinos que apresentaram síndrome cólica, visando à caracterização física, citológica e bioquímica do LP e a avaliação hematológica, bioquímica, incluindo a dosagem de proteína total, fosfatase alcalina e glicose, do fluido peritoneal e do soro. 


\section{METODOLOGIA}

0 estudo avaliou o líquido peritoneal de 12 animais, sendo dez cavalos hígidos, cinco machos e cinco fêmeas, idade entre 2-14 anos, de diferentes raças (3 manga-larga, 2 meio sangue bretão, 1 campolina e 4 sem raça definida). Também foram estudados dois animais com diagnóstico de síndrome cólica, um macho e uma fêmea, de um e quatro anos de idade, ambos da raça mangalarga.

Após exame clínico, foram coletados $4 \mathrm{~mL}$ de sangue através da punção da veia jugular para 0 exame de hemograma e aferição da bioquímica sérica.

Para análise do líquido peritoneal foi realizada a abdominocentese, segundo a técnica descrita por Peloso e Cohen (2012). Os animais foram colocados em posição de estação e o local indicado para inserção da agulha, a fim de evitar a perfuração de redes vascularizadas, foi na linha média, $2 \mathrm{~cm}$ abaixo do umbigo ou no quadrante inferior esquerdo, lateralmente ao músculo retoabdominal. Após antissepsia, a pele foi tracionada de 1 a $2 \mathrm{~cm}$ da sua posição natural para evitar o retorno de líquido após a perfuração e uma agulha $(40 \times 12)$ foi delicadamente inserida na parede abdominal e a aspiração foi feita de forma lenta, coletando 5 a $10 \mathrm{~mL}$ de LP em frascos estéreis contendo anticoagulante EDTA.

0 LP foi avaliado quanto sua aparência física, contagem total de células nucleadas (CTCN), densidade e pH. Para o exame físico, a primeira análise após a coleta foi 0 exame macroscópico da amostra e a mensuração da densidade por refratometria. Procedendo, foi realizada a avaliação do aspecto físico do derrame, a contagem global de células, a qual foi realizada em câmara de Neubauer, e a contagem diferencial em lâmina preparada, utilizando a câmara de Suta e leitura em microscopia óptica.

0 hemograma foi realizado usando 0 analisador hematológico (Mindray@) e as análises bioquímicas de proteína total, albumina, glicose e fosfatase alcalina do soro e do LP, dos animais hígidos e com cólica, foram realizadas utilizando kits bioquímicos colorimétricos específicos, com leitura por espectrofotometria.

\section{RESULTADO}

$\mathrm{Na}$ análise hematológica dos animais hígidos 0 número de hemácias variou de 5,01 x 10 células/uL (valor mínimo) a 7,83 x 10 células/uL (valor máximo); a concentração de hemoglobina apresentou-se entre $6,1 \mathrm{~g} / \mathrm{dL}$ a $10,6 \mathrm{~g} / \mathrm{dL}$. Valores do hematócrito variaram de $19,1 \%$ a $37 \%$. 0 número de plaquetas variou de $149 \times 10^{3}$ a $315 \times 10^{3}$ células/uL. No leucograma, os valores de leucócitos totais variaram de $6,3 \times 10^{3} \mathrm{a}$ $15,0 \times 10$, sendo que os segmentados de $3,2 \times 10^{3} \mathrm{a}$ $8,3 \times 10^{3}$ células/uL; linfócitos variaram de $2,4 \times 10^{3}$ a $6,8 \times 10^{3}$, monócitos de 0 a $0,7 \times 10^{3}$ células/uLe os eosinófilos de 0 a 1,2 × $10^{3}$ células/uL (Tabela 1).

Nas análises físicas, 0 líquido peritoneal apresentou uma variação de coloração variando do incolor (9\%), ao amarelo claro (63,63\%) e ao amarelo palha (18\%), que é a cor característica de cavalos saudáveis (MENDES, 2000; FEITOSA, 2004). Os animais com síndrome cólica revelaram coloração avermelhada e amarelo âmbar. Em relação à transparência, a maioria das amostras estava com aspecto límpido, contudo, os dois em síndrome de cólica apresentaram amostras levemente turvas. Nenhuma das amostras apresentou coágulos, corpos estranhos, conteúdo intestinal ou outros resíduos, mostrando que a técnica está sendo realizada de forma segura e eficaz.

Analisando por refratômetro a densidade do líquido peritoneal, os valores variaram de 1.008 a 1.038 , ressaltando que os valores mais altos nestas duas análises são referentes aos animais que apresentavam síndrome cólica. 0 pH do líquido teve variação de 6,5 a 9. (MENDES, 2000; FEITOSA, 2004) (Tabela 2). 
Tabela 1. Valores obtidos para no eritrograma, número de plaquetas e concentração de proteína total plasmática, contagem de plaquetas (plaq), leucócito total $\left(X 10^{3}\right)$; diferencial de leucócitos $\left(X 10^{3}\right)$ e concentração de fibrinogênio (mg/dL) de cavalos hígidos

\begin{tabular}{cccccccc}
\hline & He (X 106) & Hb (gdL) & VG (\%) & VCM & CHCM & Plaq & PPT g/dL \\
\hline Valor médio & 6007625 & 9,0375 & 29,58 & 43,2875 & 31,8625 & 6007625 & 7,3 \\
Desvio padrão & 2285680 & 1,50 & 6,08 & 5,16 & 1,76 & 0,51 & 0,50 \\
Valor máximo & 7830000 & 10,6 & 37 & 49,9 & 34,5 & 7830000 & 8,0 \\
Valor mínimo & 501000 & 6,1 & 19,1 & 37,8 & 30,1 & 501000 & 6,2 \\
\hline & Leuc & seg & linf & eos & mono & baso & Fib \\
\hline Valor médio & 10750 & 5960 & 4279 & 412,2 & 269 & 66,6 & 250 \\
Desvio padrão & 2597,5 & 1753,2 & 1559,3 & 424,3 & 259,1 & 70,71 & 217,3 \\
Valor máximo & 15000 & 8300 & 6600 & 1200 & 700 & 200 & 600 \\
Valor mínimo & 6300 & 3200 & 2400 & 0 & 0 & 0 & 0
\end{tabular}

He: hemácias, Hb: hemoglobina; VG (volume globular); VCM (Volume corpuscular médio); CHCM (concentração de hemoglobina corpuscular média), Plaq: Plaquetas, PPT: (proteína plasmática total,). Leucócitos (leu); neutrófilos segmentados (seg), linfócitos (linf), eosinófilos (eos), monócitos (mono); basófilos (baso); fibrinogenio (fib).

Tabela 2. Informações sobre a avaliação física (cor, aspecto, densidade e pH) do líquido peritoneal de cavalos hígidos e com cólica

\begin{tabular}{clcc}
\hline Cor & Aspecto & densidade & $\mathrm{pH}$ \\
\hline Amarelo & Grupo hígidos & & 9 \\
Amarelo claro & Límpido & 1012 & 9 \\
Amarelo & Límpido & 1012 & 9 \\
Incolor & Límpido & 1011 & 9 \\
Amarelo ouro & Límpido & 1008 & 8.5 \\
Amarelo palha & Límpido & 1012 & 8.5 \\
Amarelo palha & Límpido & 1010 & 8.5 \\
Amarelo claro & Límpido & 1012 & 9 \\
Amarelo claro & Límpido & 1012 & 8.5 \\
Amarelo claro & Límpido & 1010 & 9 \\
\hline & Límpido & 1014 & 8 \\
\hline Âmbar & Grupo cólica & & 6,5 \\
\hline Avermelhada & Turva & 1022 & 1038 \\
\hline
\end{tabular}


Na avaliação bioquímica do soro dos cavalos hígidos, verificou-se que uma concentração de proteínas totais variou de 5,28 g/dL a 9,8 g/dL; concentração de albumina de $1,8 \mathrm{~g} / \mathrm{dl}$ a 4,62g/dL; fosfatase de 339,17 $\mathrm{mg} / \mathrm{dL}$ a 1076,17 mg/dL; e a glicemia resultou de 40,52 mg/ dl a 233,19 mg/dl . No grupo cólica, observou-se a concentração sérica de 6,29 g/dL e 7,95 g/dL de proteínas totais, 1,97 g/dl (hipoalbuminemia) e 3,01 g/dL de albumina; 558,0 UI/I de fosfatase alcalina e 73,2 mg/dL de glicemia. Já no LP de cavalos hígidos, a concentração observada de proteínas totais variou de $1,0 \mathrm{~g} / \mathrm{dL}$ a $6,03 \mathrm{~g} / \mathrm{dL}$; concentração de albumina de 0,57 g/dl a 1,71 g/ $\mathrm{dL}$; fosfatase de $11 \mathrm{mg} / \mathrm{dL}$ a $56,83 \mathrm{mg} / \mathrm{dL}$; e a glicemia resultou de $74,14 \mathrm{mg} / \mathrm{dL}$ a $233,19 \mathrm{mg} / \mathrm{dL}$ os cavalos com cólica (Tabela 3).

Tabela 3. Valores das concentrações de proteínas, albumina, fosfatase alcalina e glicose do líquido peritoneal de cavalos hígidos e com cólica

\begin{tabular}{|c|c|c|c|c|c|c|c|c|}
\hline \multirow{2}{*}{$\mathrm{N}^{\circ}$ animal } & \multicolumn{2}{|c|}{ Proteína } & \multicolumn{2}{|c|}{ Albumina } & \multicolumn{2}{|c|}{ Fosfatase } & \multicolumn{2}{|c|}{ Glicose } \\
\hline & Soro & LP & Soro & LP & Soro & LP & Soro & LP \\
\hline \multicolumn{9}{|c|}{ Grupo hígidos } \\
\hline 1 & 7,62 & 1 & 3,46 & - & 512,42 & 40,33 & 40,52 & 115,09 \\
\hline 2 & 6,37 & 2,85 & 2,62 & - & 469,33 & 17.41 & 40,95 & 104.74 \\
\hline 3 & 9,4 & 2,6 & 2,78 & 1,23 & 382,25 & 21,08 & 69,4 & 117,67 \\
\hline 4 & 9,37 & 5,93 & 3,45 & 1,28 & 418 & 23,83 & 233,19 & 399,14 \\
\hline 5 & 9,8 & 1,4 & 3,33 & 0,66 & 339,17 & 11 & 74,14 & 124,14 \\
\hline 6 & 6,18 & 3,61 & 1,8 & 0,57 & 568,33 & 56,83 & 138 & 80,6 \\
\hline 7 & 8,66 & 6,03 & 3,44 & 1,28 & 715,92 & 19,25 & 85,78 & 67,24 \\
\hline 8 & 7,33 & 4,8 & 4,31 & 1,71 & 1076,17 & 46,75 & 52,16 & 125 \\
\hline 9 & 5,28 & 4,84 & 4,19 & 1,62 & 931,33 & 19,25 & 59,6 & 106,03 \\
\hline 10 & 6,12 & 5,32 & 4,62 & 1,28 & 457,42 & 21,08 & 90,52 & 152,16 \\
\hline \multicolumn{9}{|c|}{ Grupo cólica } \\
\hline 1 & 6,29 & - & 1,97 & 1,33 & 558 & 698 & - & 17,24 \\
\hline 2 & 7,95 & 6,47 & 3,01 & 2,31 & - & 38,5 & 73,2 & 0,43 \\
\hline
\end{tabular}

LP líquido peritoneal

Nos animais hígidos, a contagem diferencial de células revelou, predominantemente, a presença de neutrófilos representando de no mínimo e máximo, respectivamente $(17,6 \%-76 \%$ por campo), linfócitos de $(1 \%-44 \%$ por campo), células mesoteliais $(25 \%$ - 100\% por campo), monócitos de $(2,63 \%$ - 13\%), entre outros, neutrófilos hipersegmentados e muitas células rompidas. Tem-se então observado a presença de leucócitos e células mesoteliais em proporções consideradas normais para cavalos sadios (Tabela 4) Já nos cavalos que apresentaram síndrome cólica, a celularidade observada na lâmina estava bastante aumentada, na contagem de células total do LP na câmera de Neuwbauer, constatou-se que foram vistas hemácias no total $0,05 \times 10^{6}$ e células nucleadas no total $38,5 \times 10^{3}$, perfazendo um número maior do 
que os normais. Na contagem diferencial de células, pode ser observada, predominantemente, a presença de neutrófilos (degenerados), com mais de $75 \%$ das células, seguido de linfócitos com aproximadamente $18 \%$, sendo 0 restante, outras células como células mesoteliais reativas.

Tabela 4. Valores obtidos na diferencial de leucócitos (\%): neutrófilos segmentados, linfócitos, monócitos e células mesoteliais de cavalos hígidos

\begin{tabular}{c|c|c|c|c|c}
\hline Animais & Segmentados & Linfócitos & Monócitos & $\begin{array}{c}\text { Células } \\
\text { mesoteliais }\end{array}$ & $\begin{array}{c}\text { Total } \\
\%\end{array}$ \\
\hline \multicolumn{5}{|c}{ Grupo hígidos } \\
\hline 1 & 50,00 & 13,64 & 0,00 & 36,36 & 100 \\
\hline 2 & 0,00 & 0,00 & 0,00 & 100,00 & 100 \\
\hline 3 & 50,00 & 22,00 & 3,00 & 25,00 & 100 \\
\hline 4 & 0,00 & 0,00 & 0,00 & 100,00 & 100 \\
\hline 5 & 17,65 & 17,65 & 0,00 & 64,71 & 100 \\
\hline 6 & 34,00 & 4,00 & 0,00 & 62,00 & 100 \\
\hline 7 & 76,00 & 4,00 & 0,00 & 20,00 & 100 \\
\hline 8 & IMP & IMP & IMP & IMP & IMP \\
\hline 9 & 39,00 & 1,00 & 0,00 & 60,00 & 100 \\
\hline 10 & 39,00 & 3,00 & 3,00 & 45,00 & 100 \\
\hline
\end{tabular}

\section{DISCUSSÃO}

Nas análises físicas, o líquido peritoneal apresentou uma variação em tons claros (incolor, amarelo claro e amarelo palha) que são considerados normais e ausência de turbidez são característicos de cavalos saudáveis (NEVES et al., 2000). Nos dois animais com síndrome cólica, a coloração estava alterada, avermelhando e âmbar, além do aspecto turvo da amostra, indicando a presença do aumento de celularidade e proteínas (MENDES, 2000; DUESTERDIECK-ZELLMER et al., 2014).

$\mathrm{Na}$ comparação entre a diferença de concentração entre 0 soro e 0 plasma, todos os parâmetros bioquímicos analisados (proteínas totais, albumina e fosfatase alcalina) apresentaram maiores concentrações no soro em relação ao LP nos animais hígidos.

A média das proteínas totais no LP de equinos sadios foi de $3,952 \pm 1,80 \mathrm{~g} / \mathrm{dL}$ foi superior aos valores de 2,5 g/dL referido por Mendes et al. (2000), apesar das concentrações séricas de 7,613 $\pm 1,62 \mathrm{~g} / \mathrm{dL}$ estarem normais (KRAMER, 2000). Já, Neves et al. (2000) realizaram um estudo com equinos sadios, mensurando 0 valor referencial da proteína total no $\mathrm{LP}$, revelando que uma concentração de PPT de 1,2 $\pm 0,6 \mathrm{~g} / \mathrm{dL}$. Por sua vez, Dabareiner (2006) afirmou que a concentração de proteína presente no LP em equinos saudáveis é menor de $1,0 \mathrm{~g} / \mathrm{dL}$, observando ampla variação na concentração. Em $75 \%$ dos animais com hiperproteinemia, apresentavam uma hiperalbuminemia concomitante, indicando a presença de desidratação.

No caso de cólica, a elevação na concentração da proteína total do LP poderia indicar um extravasamento de proteínas para a cavidade abdominal, decorrente do processo inflamatório. A mensuração das proteínas se faz importante, pois auxilia no tipo de abordagem terapêutica onde se pode avaliar. Os valores mais elevados, em ambos, soro e LP, podem estar relacionados à desidratação (MATTHEWS et al., 2002).

A concentração de proteína no fluido peritoneal pode sofrer aumento diante de um peritônio inflamado, pois, com o aumento da permeabilidade peritoneal, ocorre um implemento no volume da efusão e, consequentemente, uma elevação da quantidade de proteínas (SOUT0 et al., 2019). Além do processo inflamatório, o aumento de proteínas totais no líquido peritoneal pode estar ligado ao comprometimento da parede intestinal, fazendo com que fluidos e elementos plasmáticos extravasem para dentro da alça intestinal ou cavidade peritoneal, alterando a concentração (VALADÃo et al.,2004).

A análise do LP dos animais com cólica diferiu quanto à sua aparência, contagem celular e concentração de proteínas, caracterizado por Cook e Hassel (2014) como LP normal, um líquido claro, contendo células nucleares abaixo de $5.000 / \mathrm{mL}$ e teor 
de proteínas inferior a $2.5 \mathrm{~g} / \mathrm{dL}$.

A concentração de fosfatase alcalina do LP se apresentou dentro dos valores de referência de 0-161UI/L nos animais saudáveis, contudo, observouse ampla variação nos animais com cólica. Entretanto, como o valor médio no soro divergiu do LP e foi superior ao de referência, sugere-se uma causa extraabdominal. Como a fosfatase alcalina é uma enzima pouco específica, pode ser encontrada em células de diferentes órgãos (intestino, rins, fígado e ossos) e seu aumento pode ser pouco específico (TRHALL, 2014). A análise da fosfatase alcalina é um guia importante para distúrbios hepatobiliares e ósseos, e elevações desta enzima são observadas em obstruções extrahepáticas (MOTTA, 2000). Em equinos, as principais causas de aumento da atividade da FA séricas estão relacionadas à colestase ou à produção de isoenzima óssea por osteoblastos ou também pode ser observada pelo efeito do estresse (QUEIROZ et al, 2016)

A concentração da glicose do LP foi superior a sérica, concordando Saulez et al. (2005) que relataram que as concentrações de glicose peritoneal eram discretamente superiores às do sangue. A média do soro está dentro dos padrões e do líquido peritoneal se adequou ao valor de referência de 74-203 mg/ $\mathrm{dL}$ (FEITOSA, 2004). Moreira et al. (2015) relataram a concentração de 128,67 md/dL como valor médio da concentração da glicose do líquido peritoneal em animais sadios.

Entretanto, um animal hígido do experimento apresentou a concentração de glicose, no soro e no LP, muito superior aos demais animais estudados, elevando a média do grupo. 0 aumento da glicose pode estar relacionado com a ingestão de alimentos, prévios a coleta ou mesmo uma colheita dificultosa. As concentrações de glicose no sangue e no líquido peritoneal são, geralmente, estreitamente correlacionadas (SAULEZ et al., 2005). Já os animais com cólica apresentaram concentrações muito baixas no LP, concordando com Campebell et al. (2007) que observaram que em cavalos apresentando síndrome cólica os níveis de glicose estão diminuídos pelo crescimento acelerado de bactérias, na sua maioria gram-negativas.

0 aumento da celularidade no líquido peritoneal pode ser observado em inflamações agudas, sendo os neutrófilos as células predominantes (BARROS et al., 2016). 0 número de hemácias poderá apresentar valor elevado no líquido peritoneal em casos de lesões graves do peritônio (DUESTERDIECK-ZELLMER et al, 2016).

Uma marca da diferença observada na leitura das lâminas, a presença de leucócitos e células mesoteliais, em proporções consideradas normais para cavalos sadios.

Já nos cavalos que apresentaram síndrome de cólica, a celularidade observada na lâmina estava bastante aumentada, observando uma leucocitose por neutrofilia, semelhante ao observado por Di Filippo et al. (2009) em cavalos com obstrução.

Aanálise do líquido peritoneal é uma ferramenta eficaz, que colabora para guiar o tratamento adequado em animais que apresentam a síndrome cólica, de forma a encurtar o tempo de tratamento direcionando o tratamento, concedendo ao animal um melhor prognóstico.

Apesar dos resultados, há a necessidade de um número maior de animais com cólica, possibilitando a realização de análise estatística comparativa e a caracterização populacional, com a diferenciação de acordo com a origem da afecção, uma vez que a síndrome de cólica apresenta diferentes agentes causais.

A técnica de coleta de LP utilizada não influenciou na qualidade da amostra e a análise física, bioquímica e celular do líquido peritoneal pode auxiliar na avaliação de cavalos com cólica, mostrando-se ser uma técnica simples, de baixo custo e acessível à medicina equina. 


\section{CONCLUSÃo}

Com esse estudo pode-se concluir que a avaliação do líquido peritoneal é de realização factível na rotina veterinária pela acessibilidade, rapidez e baixo custo. 0 s resultados obtidos neste estudo foram compatíveis com outros autores, consolidando os valores reportados, reafirmando a sua utilização como ferramenta diagnóstica.

\section{AGRADECIMENTOS}

A Fundação de Amparo à Pesquisa do Estado de Alagoas, pelo apoio na realização.

\section{REFERÊNCIAS}

BARROS, I.O.; FONSECA, N.B.S.; NUNES, T.L. SPAGNOLO, J.D.; SANTOS, J.P.A.; NETO, A.S.; OLIVEIRA, M.G.C.; NOGUEIRA, A.F.S.; SOUSA, R.S.; SILVA, L.C.L.C.; BARRÊTO JÚNIOR, R.A. Resposta inflamatória peritoneal de asininos (Equus asinus) submetidos à ovariectomia por laparotomia $\mathrm{e}$ laparoscopia. Arquivo Brasileiro de Medicina Veterinária e Zootecnia, v.70, n.5, p.1468-1476, 2018

BROWN, C.M., BERTONE, J. The 5 minutes veterinary consult equine. Baltimore: Lippincott Williams \& Wilkins, 2002. 1154p.

CAMPEBELL, R.C.; PEIRÓ, J.R.; ROSA, P.C.S.; VALADÃO, C.A.A.; BECHARA, G.H. Endotoxemia por lipopolissacarídeo de Escherichia coli, em eqüinos: efeitos de antiinflamatórios nas concentrações sérica e peritoneal do fator de necrose tumoral alfa (TNFalfa) Arquivo Brasileiro de Medicina Veterinária e Zootecnia. v.59, n.4, p.837-843, 2007

COOK, V.L.; HASSEL, D.M. Evaluation of the Colic in Horse s: Decision for Referral. Veterinary Clinical Equine, v.30; p.383-398, 2014.

DABAREINER, R.M. Peritonite. In: SMITH, B.P.
Medicina Interna de Grandes Animais. 3. ed. Manole: São Paulo, 2006. p. 668-674.

DeHEER, H.L.; PARRY, B.W.; GRINDEM, C.B. Peritoneal fluid. In: COWELL, R.L.; TYLER, R.D. (ed.). Diagnostic cytology and hematology of the horse. 2. ed. St. Louis: Mosby, 2002.

DI FILIPPO, P.A. et al. Perfil eletroforetico das proteínas séricas e do líquido peritoneal de equinos submetidos a obstrução experimental do duodeno, íleo e colón maior. Ciência Animal Brasileira, v.11, p.9-12, 2010

DI FILIPPO, P.A. et al. Proteinograma sérico e do líquido peritoneal de equinos submetidos a orquiectomia. Ciência Rural. v.44, p.2221-7, 2014.

DI FILIPPO, P. A.; ALVES, A. E.; HERMETO, L.C.; SANTANA, A.E. indicadores bioquímicos séricos e do líquido peritoneal de equinos submetidos à obstrução intestinal. Ciência Animal Brasileira, Goiânia, v.13, n.4, p. 504-511, 2012.

DI FILIPPO, P.A.; MASCARENHAS, L. D. A S.; GOMES, F.R.; RODRIGUES, A.B.F.; CARVALHO, R.S.; GRAÇA, F.A.S. Efeitos da castração sobre características físico-químicas celulares do líquido peritoneal de equinos Veterinária Notícias, V. 22 N. 2, 2016.

DI FILIPPO, P.A.; SANTANA, A.E.; NOGUEIRA, A.F.S.; ANAI, L.A.; CAMPOS FILHO, E. Características celulares e bioquímicas do líquido peritoneal de equinos submetidos à obstrução experimental do duodeno, íleo e cólon maior. Arquivo Brasileiro de Medicina Veterinária e Zootecnia, v. 61, n. 6, p. 1281-1289, 2009.

DUESTERDIECK-ZELLMER, K. F.; RIEHL, J. H.; MCKENZIE, E. C.; FIRSHMAN, A. M; PAYTON, M. E.; GORMAN, M. E. effects of abdominocentesis technique on peritoneal fluid and clinical variables in horses. Equine Veterinary Education, n. 26, v. 5, p. 262-268, 2014.

FEITOSA, F.L.L. Semiologia Veterinária. A Arte do Diagnostico. Roca. São Paulo, 2004.

KRAMER, J.W. Normal hematology of the horse. 
In: FELDMAN, B.F. et al. Schalm's veterinary

hematology. Canadá: Lippincott Williams e Wilkins, 2000. Cap.4, p.1069-1074.

LHAMAS, C.A.; DUARTE, C.A.; LÜBECK, I; SILVA, M.N.G.; LEITE, C.T.; PEREIRA, E.P.; ROSCHILDT, K.; BERNARDON, F. Influência do parasitismo intestinal sobre os parâmetros hematológicos e de líquido peritoneal em equinos de tração. Arquivo Brasileiro de Medicina Veterinária e Zootecnia v. 67, n. 2, p. 381-390, 2015.

MATTHEWS, S.; DART, A.J.; REID, S.W.J.; DOWLING, B.A.; HODGSON, D. R. Predictive values, sensitivity and specificity of abdominal fluid variables in determining the need for surgery in horses with an acute abdominal crisis. Aust. Veterinary Journal, v. 80, n. 3, p. 132-136, 2002.

MENDES, L.C.N. et al. Avaliação Laboratorial do Fluido Peritoneal em Modelos Experimentais Utilizados para Indução de Reação Inflamatória Intra-Abdominal em Equinos. Continuous Education Journal CRMV-SP, São Paulo, v. 3, n. 3, p. 21-27, 2000.

MOTTA, V.T. Bioquímica Clínica: métodos e interpretações. 2. ed. Rio de Janeiro: Médica Missau, 2000.

NEVES, M.M.; MARQUES J.R., A.P.; ALVES, G.E.S.; FARIA, E.P. Valores referenciais da análise do líquido peritoneal de equinos sadios. Ciência Rural, v. 30, n. 5, p. 809-811, 2000.

NOGUEIRA, A.F.S.; DI FILIPPO, P.A.; ANAI, L.A.; PEREIRA, G.T.; SANTANA, A.E. Proteinograma sérico e do líquido peritoneal de equinos hígidos e daqueles submetidos à obstrução intestinal experimental.

Ciência Rural, v. 43, n. 11, p. 2018-2024, 2013.

PELOSO J.G.; COHEN N.D. Use of serial measurements of peritoneal fluid lactate concentration to identify strangulating intestinal lesions in referred horses with signs of colic. Journal of American Veterinary Medical Association, v. 240, n. 10, p. 1208-1, 2012.

PIHL, T.H.; SCHEEPERS, E.; SANZ, M.; GODDARD, A.; PAGE, P.; TOFT, N.; ANDERSEN, P.H.; JACOBSEN,
S. Influence of Disease Process and Duration on Acute Phase Proteins in Serum and Peritoneal Fluid of Horses with Colic. Journal of Veterinary Internal Medicine, n. 29, p. 651-658, 2015.

SAULEZ, M. N.; CEBRA, C. K.; DAILEY, M. Comparative biochemical analyses of venous blood and peritoneal fluid from horses with colic using a portable analyser and an in-house analyser. Veterinary Record, $v$. 157, p. 217-223, 2005.

SOUTO, P.C.; DA FONSECA, L.A.; OROZCO, A.M.O.; LOPEZ, C.J.R.; ERMITA; P.A.N.; DE CARVALHO FILHO, W.P.; GIRARDI, F.M. Acute-Phase Proteins of Healthy Horses and Horses Naturally Affected by Colic Syndrome Journal of Equine Veterinary Science, $n$. 80, p. 1-4, 2019.

STOCKHAM, S.L., SCOTT, M.A. Fundamentals of veterinary clínical pathology. Ames: lowa State Press, 2002. 610p.

THOMASSIAN, A. Enfermidades dos cavalos. 4. ed. São Paulo: Varela, 2005. 335p.

VALADÃO, C.A.A.; PUELKER, R.Z.; DE SOUZA, A.H. Características do líquido peritoneal de eqüinos normais após punção cecal percutânea. Ciência Rural, v. 34, n. 6, p. 1817-1820, 2004.

VIEIRA, V; LEMOS, G.L.; DEFANTI, PETRUCCI, V.; DI FILIPPO, P.A. Cultura do líquido peritoneal utilizada como indicador de prognóstico em equinos com obstrução estrangulativa do intestino delgado. Revista Investigação, v. 17, n. 4, 2018.

Recebido em: 26/07/2019

Aceito em: 07/10/2019 